Wesleyan University

From the SelectedWorks of Charles A. Sanislow, Ph.D.

December, 2004

Stressful life events as predictors of functioning: findings from the Collaborative Longitudinal Personality Disorders Study

\author{
Maria E. Pagano \\ Andrew E. Skodol \\ Robert L. Stout \\ M. Tracie Shea \\ Shirley Yen, et al.
}




\section{Stressful life events as predictors of functioning: findings from the Collaborative Longitudinal Personality Disorders Study}

Pagano ME, Skodol AE, Stout RL, Shea MT, Yen S, Grilo CM, Sanislow CA, Bender DS, McGlashan TH, Zanarini MC, Gunderson JG. Stressful life events as predictors of functioning: findings from the Collaborative Longitudinal Personality Disorders Study.

Acta Psychiatr Scand 2004: 110: 421-429. ㄷ Blackwell Munksgaard 2004.

Objective: Although much attention has been given to the effects of adverse childhood experiences on the development of personality disorders (PDs), we know far less about how recent life events influence the ongoing course of functioning. We examined the extent to which PD subjects differ in rates of life events and the extent to which life events impact psychosocial functioning.

Method: A total of 633 subjects were drawn from the Collaborative Longitudinal Personality Disorders Study (CLPS), a multi-site study of four personality disorders - schizotypal (STPD), borderline (BPD), avoidant (AVPD), obsessive-compulsive (OCPD) - and a comparison group of major depressive disorders (MDD) without PD.

Results: Borderline personality disorder subjects reported significantly more total negative life events than other PDs or subjects with MDD. Negative events, especially interpersonal events, predicted decreased psychosocial functioning over time.

Conclusion: Our findings indicate higher rates of negative events in subjects with more severe PDs and suggest that negative life events adversely impact multiple areas of psychosocial functioning.

\author{
M. E. Pagano' ${ }^{1}$ A. E. Skodol ${ }^{2}$, \\ R. L. Stout ${ }^{3}$, M. T. Shea ${ }^{1}$, S. Yen ${ }^{1}$ \\ C. M. Grilo" , C. A. Sanislow 4 \\ D. S. Bender', T. H. McGlashan", \\ M. C. Zanarini ${ }^{5}$, J. G. Gunderson ${ }^{5}$ \\ 1 Department of Psychiatry and Human Behavior, Brown \\ University Medical School, Providence, Rl, ${ }^{2}$ New York \\ State Psychiatric Institute, Columbia University College \\ of Physicians and Surgeons, New York, NY, ${ }^{3}$ Decision \\ Sciences Institute, Providence, Rl, ${ }^{4}$ Department of \\ Psychiatry, Yale University School of Medicine, New \\ Haven, CT, ${ }^{5}$ McLean Hospital, Harvard Medical School, \\ Belmont, MA, USA
}

Key words: personality disorders; stress; life change events; psychosocial functioning

Maria E. Pagano, Department of Psychiatry and Human Behavior, Brown University Medical School, Box G-BH, Providence, RI 02912, USA.

E-mail: maria_pagano@brown.edu

Accepted for publication May 12, 2004

\section{Introduction}

Personality disorders (PDs) are thought to result from interactions between temperamental vulnerabilities (diatheses) and adverse life experiences (stressors) (1). Heritable personality traits influence both the occurrence of and exposure to stressors $(2,3)$ and how they are perceived and managed. The joint effects of diatheses and stress increase liability to psychiatric illness (4), in general, and over time may produce the quasi-stable constellations of maladaptive traits and behaviors and pervasive dysfunctions that characterize PDs (5).

Particular personality traits, such as neuroticism from the five-factor model of personality (6), have been demonstrated in empirical research to increase both exposure $(7,8)$ and sensitivity $(8,9)$ to traumatic life experiences. Neuroticism, or negative emotionality or temperament as it is known in the three-factor model of personality $(10,11)$, represents a tendency to see and react to the world as threatening, problematic, and distressing. People with high levels of neuroticism are prone to make negative cognitive appraisals of situations requiring coping, which in turn tend to make a stressful event more stressful, or to choose coping mechanisms that are ineffective (12). People with high levels of neuroticism have increased exposure to stress because they place themselves in interpersonal and other situations, in which stressful events (e.g. arising from conflict) are more likely to occur.

Personality disorders are characterized by high levels of neuroticism $(6,13)$ and widespread 
psychosocial dysfunction, especially in interpersonal relationships (14). Thus, patients with PDs would be expected to experience many negative life stressors and to react poorly to them. Much more attention has been paid in the literature to the potential role of adverse childhood experiences, such as physical or sexual abuse or neglect, in the development of PDs (15) than to the effects of recent life events in dictating the ongoing course of symptoms and functioning in patients with PDs. Perry $(16,17)$ has found that patients with borderline personality disorder (BPD) experienced elevated rates of life events over time, accompanied by increased rates of depressive symptoms and episodes. Kelly et al. (18) found a direct relationship between functioning and suicide; patients with BPD who were low on overall social adjustment were over 16 times more likely to have attempted suicide that patients with major depression. Although recent life events were not predictive of suicide attempts, it is likely that they contributed to the lower levels of social functioning. Thus, the effects of life events on psychosocial functioning in patients with PDs may play a significant role in the crises that punctuate the clinical course of many patients with PDs and often are the critical determinants of their seeking or receiving treatment.

Based on the findings of the reviewed work, the current study investigated four aims regarding the impact of recent life events on psychosocial functioning in patients with PDs. First, we tested whether elevated rates of life events were particular to patients with BPD, or generalized across PDs from other DSM-IV clusters. Second, we tested whether (a) life events have short-term effects on functioning, and (b) whether a given life event has the same effect on functioning for all the PDs. Third, because some kinds of events may affect only one or two domains of functioning (e.g. work functioning) while others may affect functioning in many domains, we tested for both role-specific and general effects of stressors. Fourth, we tested whether subjects with high neuroticism were more functionally impaired in response to stressful life events.

\section{Material and methods}

The Collaborative Longitudinal Personality Disorders Study (CLPS) is a multi-site, naturalistic, prospective study of four PD groups, schizotypal (STPD), borderline (BPD), avoidant (AVPD) and obsessive-compulsive (OCPD), and a comparison group of major depressive disorders (MDD) without PD. These four PDs were selected on the basis of the phenomenological distinctions and their divergent clinical, conceptual, and empirical bases, and also corresponded to the four psychobiological dimensions of psychopathology proposed by Siever and Davis (19). The overall aims, design, assessment methodology, and demographic characteristics of the sample are detailed elsewhere (20). Following is an overview of the study participants and assessment procedures relevant to the present investigation.

\section{Subjects}

Participants between the ages of 18 and 45 years were recruited from treatment clinics affiliated with the four CLPS sites. Additional individuals who had been in current or past treatment were recruited from fliers and advertisements. Individuals with any of the following were excluded from participation: acute substance intoxication or withdrawal; active psychosis; IQ less than or equal to 85; cognitive impairment; or a history of either schizophrenia, schizophreniform, or schizoaffective disorders. Individuals were eligible to participate if they met diagnostic criteria as assessed by the Diagnostic Interview for DSM-IV Personality Disorders (DIPD-IV) (21) for at least one of the four PDs targeted in the CLPS (STPD, BPD, AVPD, OCPD) or if they met criteria for the comparison group, major depressive disorder as assessed by the Structured Clinical Interview for DSM-IV Axis I Disorders - patient version (SCIDI/P) (22) without PD. Interviewers' DIPD-IV diagnoses had to receive convergent support from one other method of axis II assessment, either the self-report Schedule for Non-adaptive and Adaptive Personality (SNAP) (23) or the clinician-rated Personality Assessment Form (PAF) (24). Although each subject was assigned to one of the study disorder groups based upon the number and severity of diagnostic criteria identified, the presence of other comorbid PDs was also assessed. Whereas $45 \%$ of the AVPD and $52 \%$ of the OCPD participants had no additional diagnosed $\mathrm{PD}$, the majority of STPD and BPD subjects had at least two additional PD diagnoses [see McGlashan et al. (25) for further details on diagnostic comorbidity]. Interviewers had masters or doctoral level training (or equivalent clinical experience) in a mental health related discipline. Each participant signed an informed consent, approved by the institutional review boards at their respective sites/institutions.

The total CLPS study group consisted of 668 participants. Participants were interviewed at 6 months, 1 year, 2 years, and 3 years following the baseline assessment. We examined the 633 participants ( $95 \%$ of sample) with at least 1 year of 
complete follow-up data on measures used in this study. A total of $484(76 \%)$ of the participants were Caucasian, 77 (12\%) were African-American, $54(9 \%)$ were Hispanic, and $18(3 \%)$ other minorities, three hundred and twenty-one $(65 \%)$ were female. Based on education and current employment, the Hollingshead-Redlich score (26) found $36 \%$ of the sample from the highest two social class categories (levels I and II), 28\% from level III, and $36 \%$ from the lowest categories (levels IV and V). The mean age was $32.8(\mathrm{SD}=8.1)$. Overall, participants in the four PD study groups were assigned a mean of $1.4(\mathrm{SD}=1.6)$ additional PDs. The study sample distribution in terms of age, gender, race, socioeconomic status, and PD comorbidity were virtually identical to the total sample. There were no demographic differences between the current study sample and participants not included because of absence of complete follow-up data.

\section{Measures}

Diagnostic Interview for DSM-IV Personality Disorders This semi-structured interview consists of questions that assess each criterion of the 10 DSM-IV PDs. Inter-rater and test-retest reliability of the DIPD-IV (kappa) for the four study PDs were 0.68 and 0.69 for BPD, 0.68 and 0.73 for AVPD, and 0.71 and 0.74 for OCPD, respectively. The inter-rater reliability sample was insufficient to calculate kappa for STPD; the test-retest kappa for STPD was 0.64 (21).

Neuroticism Neuroticism levels are assessed using the Revised NEO Personality Inventory (NEOPI-R) (27). The NEO-PI-R is a 240 -item self-report instrument that provides a comprehensive assessment of the five-factor model of personality; these domains include neuroticism, extraversion, openness to experience, agreeableness, and conscientiousness. Internal consistency reliabilities for the five domain scales range from 0.86 to 0.95 (28). The 48-item NEO-PI-R neuroticism scale was used.

Psychosocial functioning The longitudinal interval follow-up evaluation (LIFE) (29) is a semi-structured interview rating system with demonstrated reliability for assessing the longitudinal course of psychiatric disorders and psychosocial functioning. Psychosocial functioning in the LIFE is rated for each month of each interval and includes the following domains: 1) employment; 2) household duties; 3) interpersonal relations with family members and friends; 4) recreation: frequency and enjoyment level; 5) overall satisfaction with life; 6) an assessment of overall functioning separate from symptoms. In addition, Global Assessment of Functioning (GAF) ratings for each month are made by the interviewer.

Life Events Assessment Life events are assessed using the Life Events Assessment (LEA). Subjects are asked if any of a list of 82 events or circumstances occurred since the last follow-up interview. Perry et al. (17) has used a similar format to assess the types and role of life events in the course of PDs.

LEA items were grouped by stress domain categories: 27 items pertained to work or school (20 negative, seven positive); 16 items pertained to family or living circumstances (10 negative, six positive); 13 items referred to love relations with a spouse or partner (eight negative, five positive); 12 items referred to crime and legal matters (10 negative, two positive); seven items referred to financial matters (five negative, two positive); and four items pertained to physical health (three negative, one positive); three items referred to social matters (three negative, zero positive). In total, 59 items were considered to be negative and 23 items were considered to be positive events. Table 1 shows each item within each stress domain.

Subjects provided the onset date for endorsed stressful events. For each month of the follow-up period, a dichotomous variable was created to represent the presence or absence of a domain specific stressor within that month. The total number of stressors reported during the follow-up study period was compared across domain categories. Low associations were found between items within stress domain categories $(r=0.01-0.37)$ and between stress domain categories $(r=0.07-$ 0.34 ), suggesting that stress reported in one domain did not highly correlate with stress reported in another.

Analyses

We approached our data analysis strategy in several ways. First, to compare rates of life events between PD and MDD groups, we totaled the cumulative number of stressful life events reported each month across the follow-up period. Analysis of variance (ANOVA) tests were performed to compare the total number of stressors reported during the follow-up period among the PD and MDD groups.

Second, using our prospective methodology, we examined the timing of life events in relation to 
Pagano et al.

\begin{tabular}{|c|c|}
\hline Life events domain & \\
\hline Work/school & \\
\hline Started school/training program & Graduated from school/training program* \\
\hline Unable to enter school/training program & Unable to stay in school/training program \\
\hline Started work for first time & Returned to work after not working for a long time \\
\hline Changed jobs for a better one* & Changed jobs for a worse one \\
\hline Had trouble with a boss & Did not get expected salary increase \\
\hline Demoted at work & Took salary cut without demotion \\
\hline Found out that was not going to be promoted at work & Promoted* \\
\hline Got substantial salary increase without promotion* & Had important success at work* \\
\hline Laid off & Fired \\
\hline Quit job & Started a business or profession \\
\hline Expanded business practice & Suffered a business loss or failure \\
\hline Sharply reduced work load* & Retired* $^{*}$ \\
\hline Entered armed services & Stopped work, not retirement, for extended period \\
\hline Left armed services & \\
\hline Family/living matters & \\
\hline New person moved into the household & Person moved out of the household \\
\hline Family member other than spouse or child died & Moved to better residence or neighborhood* \\
\hline Build a home or had a home built* & Moved to a worse residence or neighborhood \\
\hline Birth of a first child* & Lost home through fire/flood/other disaster \\
\hline Birth of child after the first ${ }^{*}$ & Abortion \\
\hline Miscarriage or still birth & Found out that cannot have children \\
\hline Child died & Adopted a child* \\
\hline Started menopause & Became pregnant* \\
\hline Love relations & \\
\hline Became engaged $^{*}$ & Engagement was broken \\
\hline Married* ${ }^{*}$ & Started a love affair* \\
\hline Relations declined without separation or divorce & Married couple separated \\
\hline Divorce & Spouse/mate relations changed for better* \\
\hline Respondent engaged in marital infidelity & Spouse/mate engaged in marital infidelity \\
\hline Spouse/mate died & Couple reunited after separation* \\
\hline Ended a love affair & \\
\hline Crime/legal matters & \\
\hline Physically assaulted or attacked & Robbed \\
\hline Burglarized & Involved in a lawsuit \\
\hline Accused of something for which a person could go to jail & Got involved in a court case \\
\hline Convicted or found guilty of a crime & Acquitted or found innocent of a crime* ${ }^{*}$ \\
\hline Released from jail* & Did not get out of jail when expected to \\
\hline Financial matters & \\
\hline Had financial improvement not related to work & Started buying a car, furniture, or other large item \\
\hline Suffered financial loss not related to work & Repossession of a car, furniture, or large item \\
\hline Went on welfare & Took out a morgage \\
\hline Went off welfare & \\
\hline Health & \\
\hline Physical health improved & Severe physical illness started/worsened \\
\hline Serious injury occurred/worsened & Unable to get treatment for serious illness \\
\hline Social & \\
\hline Broke up with a friend & Close friend died \\
\hline Went on a trip other than a vacation trip & \\
\hline
\end{tabular}

\section{Work/school}

Started work for first time

Changed jobs for a better one

trouble with a boss

Found out that was not going to be promoted at work

Got substantial salary increase without promotion*

Expanded business practice

Sharply reduced work load*

Entered armed services

Family member other than spouse or child died

Child died

Started menopause

Love relations

Relations declined without separation or divorce

Divorce

Physically assaulted or attacked

Burglarized

Convicted or found guilty of a crime

Released from jail

Went on welfare

Went off welfare

Physical health improved

Social

Went on a trip other than a vacation trip

Graduated from school/training program*

to stay in schoo/training program

Changed jobs for a worse one

Promoted*

Had important success at work*

Suffered a business loss or failure

Retired*

Moved to better residence or neighborhood*

Abortion

Adopted a child

Engagement was broken

Started a love affair*

Spouse/mate engaged in marital inficelity

Got involved in a court case

Acquitted or found innocent of a crime*

Started buying a car, furniture, or other large item Repossession of a car, furniture, or large item

ook out a morgage

*Positive life event.

monthly functioning ratings. We first identified the date of the event, and then examined the functioning in the months preceding and following each event. We employed random effects regression methods to test an interrupted timeseries model for functioning around the time of the event. We tested for a step-change in functioning beginning in the month of the event and continuing afterwards. Preliminary analyses suggested that a linear timeseries model, allowing for a change in slope and intercept at the time of the event, was adequate. The analysis assumed that the correlations among the time points were unstructured, the least restrictive assumption available.

For each measure of psychosocial functioning, nine longitudinal random effects regression models were constructed to look at the relationships between total negative life events and eight domain specific life events on functioning. Prior work and preliminary analyses suggested testing for two interactions between subject characteristics and stressful life events in predicting functioning levels. Because we were interested in exploring possible differences in the extent to which life 
events impacted functioning among different PDs, we entered PD diagnosis and an interaction term between PD diagnosis and life events into each model. In addition, since prior work has shown neuroticism to moderate the extent to which subjects report stressful life events, neuroticism scores and an interaction between neuroticism and life events were entered in each model.

Random effect regression analyses were performed with age, gender, education, number of positive events, and baseline psychosocial functioning scores as covariates. In order to reduce potential collinearity (30), baseline assessments of neuroticism and psychosocial functioning scores were centered by subtracting the sample mean from each score. Effect sizes were calculated and reported in terms of the effect size index $d$, using Cohen's categories of 'small' $(d=0.2)$, 'medium' $(d=0.5)$, and 'large' $(d=0.8)$ (31). A partial Bonferroni-corrected alpha level of $P<0.01$ was used for statistical significance. Analyses were performed using SAS version 8.2.

\section{Graphing the course of functioning before and after life event}

To compliment and extend the random effect regression analyses, we graphed the time course of psychosocial functioning 12 months prior to and following the time of the life event. For subjects who reported a life event under consideration, we designated the month that the life event occurred for that individual as month 0 . Psychosocial ratings were then assembled and plotted relative to that time point, up to 12 months prior to the life event and 12 months afterward.

\section{Results}

Diagnostic group differences in number of stressful life events

The average number of total negative stressors reported by 633 participants over the course of
3 years was 6.3 stressful events $\quad(\mathrm{SD}=3.7$; range $=0-31)$. The mean levels of LEA events reported during the follow-up period by stress domain category were compared among the PD and MDD groups (Table 2). Significant differences between diagnostic groups were found for negative crime/legal events $(F=4.7$, d.f. $=4, P<0.001)$; post hoc Duncan tests showed that BPD and STPD subjects reported significantly more crime/legal events than AVPD and OCPD subjects $(P<$ 0.01 ). Significant group differences were found for total negative events $(F=5.9$, d.f. $=4, \quad P<$ $0.0001)$, health events $(F=3.3, \quad$ d.f. $=4$, $P<0.01)$, and social matters $(F=4.14$, d.f. $=4$, $P<0.01)$; BPD subjects reported significantly more total negative in comparison with all other groups $(P<0.01)$, and significantly more health and social stressors than AVPD subjects $(P<0.01)$. Significant group differences were found for positive events $(F=3.5$, d.f. $=4$, $P<0.01)$; MDD subjects reported significantly more positive events than BPD and STPD subjects. Diagnostic groups did not differ in frequency of negative events in the domains of work/school, family matters, love relations, or financial matters.

Diagnostic group differences in neuroticism

The mean neuroticism score for the sample was $74.12(\mathrm{SD}=8.81)$. Significant differences in neuroticism scores were found between diagnostic groups $(F=9.51$, d.f. $=4, P<0.0001)$. AVPD subjects reported the highest level of neuroticism $(\mathrm{M}=76.99)$, followed by $\mathrm{BPD}$ subjects $(\mathrm{M}=$ 75.21), STPD subjects $(M=73.22), \quad$ OCPD subjects $(M=72.64)$, and then MDD subjects $(\mathrm{M}=70.52)$. Post hoc Duncan tests found AVPD subjects to have significantly higher levels of neuroticism in comparison with STPD, OCPD, and MDD subjects, and BPD subjects to have significantly higher levels of neuroticism in comparison with MDD subjects. BPD subjects did not
Table 2. Comparison of the frequency of life events reported over 3 years among PD groups

\begin{tabular}{lcccccc}
\hline Stressor & $\begin{array}{c}\text { Total } \\
{[633(100 \%)]}\end{array}$ & $\begin{array}{c}\text { STPD } \\
{[84(13 \%)]}\end{array}$ & $\begin{array}{c}\text { BPD } \\
{[160(25 \%)]}\end{array}$ & $\begin{array}{c}\text { AVPD } \\
{[150(24 \%)]}\end{array}$ & $\begin{array}{c}\text { OCPD } \\
{[148(23 \%)]}\end{array}$ & $\begin{array}{c}\text { MDD } \\
{[91(14 \%)]}\end{array}$ \\
\hline Stress domain & & & & & & \\
Total negative* & $6.3(3.7)$ & $6.3(3.7)$ & $7.6(3.9)$ & $5.2(3.4)$ & $6.5(3.7)$ & $5.9(3.6)$ \\
Work/school & $1.6(1.6)$ & $1.7(1.9)$ & $1.8(1.8)$ & $1.3(1.2)$ & $1.6(1.5)$ & $1.5(1.6)$ \\
Family/living matters & $1.5(1.5)$ & $1.5(1.6)$ & $1.7(1.6)$ & $1.3(1.4)$ & $1.5(1.6)$ & $1.5(1.6)$ \\
Love relations & $0.7(1.0)$ & $0.7(1.1)$ & $0.9(1.0)$ & $0.6(0.8)$ & $0.8(0.7)$ & $0.7(1.1)$ \\
Crime/legal matters* & $0.6(1.0)$ & $0.8(1.3)$ & $0.7(1.1)$ & $0.4(0.9)$ & $0.4(0.7)$ & $0.5(0.8)$ \\
Health* & $0.5(0.8)$ & $0.5(0.8)$ & $0.7(1.0)$ & $0.4(0.7)$ & $0.6(0.8)$ & $0.4(0.7)$ \\
Financial matters $_{\text {Social matters* }}^{*}$ & $0.4(0.7)$ & $0.4(0.8)$ & $0.4(0.7)$ & $0.4(0.7)$ & $0.4(0.7)$ & $0.3(0.7)$ \\
Positive* $^{*}$ & $0.7(0.9)$ & $0.7(0.9)$ & $0.9(1.0)$ & $0.6(0.8)$ & $0.8(1.0)$ & $0.7(0.8)$ \\
& $2.7(2.0)$ & $2.4(2.1)$ & $2.6(2.0)$ & $2.5(1.9)$ & $3.0(2.1)$ & $3.3(1.9)$ \\
\hline
\end{tabular}

Values are in mean (SD).

${ }^{*} P<0.01$. 
differ from AVPD, OCPD, and STPD subjects in average mean levels of neuroticism.

\section{Longitudinal random effect analysis results}

Table 3 presents the results of the longitudinal random effect analyses of the relationships of domains of life events in the prior month to domains of psychosocial functioning. The focus of these analyses was to determine the effect of specific domains of life events on specific domains of psychosocial functioning and the extent to which these relationships differed among PD diagnostic groups and neuroticism levels. In-depth examination of diagnostic group and demographic differences in functional impairment is presented elsewhere (13).

Main effects of domains of life events on domains of functioning Significant relationships between specific domains of life events and domains of functioning that had an alpha level of $P<0.01$ are highlighted in Table 3. Experiencing a work life event was associated with significantly lower levels of work functioning, but not with any other areas of functioning. Family and negative love life events were associated with significantly more impairment in GAF, satisfaction, GSA, employment, and mate relations. Legal or crime events negatively impacted GAF and household functioning. Financial events did not significantly predict functioning levels in any domain. Significant main effects were found for health life events on the psychosocial domains of GAF, satisfaction, and household functioning. Social life events negatively impacted the functioning domains of GAF, recreation, satisfaction, GSA, employment, and household. Cumulative positive events were predictive of improvements in satisfaction, GSA, and mate relations. Cumulative negative life events negatively impacted the functioning domains of GAF, satisfaction, GSA, employment, and mate relations. Effect size estimates for significant main effect findings of life events on functioning ranged from $d=0.20-0.25$.

The longitudinal associations of life events and functioning are shown in visual form for one of the significant findings shown in Table 3. Figure 1

Table 3. Effects of stress type on functioning

\begin{tabular}{|c|c|c|c|c|c|c|c|c|c|}
\hline \multirow[b]{2}{*}{ Functioning domain } & \multicolumn{8}{|c|}{ Stress domain } & \multirow[b]{2}{*}{ Cumulative numbe } \\
\hline & Work & Family & Love & Crime & Finance & Health & Social & Positive & \\
\hline \multicolumn{10}{|l|}{ GAF } \\
\hline$\beta$ & 0.09 & -0.25 & -2.20 & -1.21 & -1.40 & -3.91 & -0.07 & 0.18 & -0.34 \\
\hline$F$ & 2.30 & 14.66 & 16.68 & 16.49 & 1.01 & 13.45 & 10.24 & 4.88 & 26.46 \\
\hline$P$ & 0.1364 & 0.0001 & 0.0001 & 0.0001 & 0.4941 & 0.0002 & 0.0014 & 0.0272 & 0.0001 \\
\hline \multicolumn{10}{|l|}{ Friendship } \\
\hline$\beta$ & 0.05 & 0.03 & -0.03 & 0.16 & -0.08 & 0.15 & 0.06 & -0.06 & 0.02 \\
\hline$F$ & 0.03 & 0.65 & 0.36 & 0.37 & 0.20 & 1.25 & 2.56 & 2.19 & 0.68 \\
\hline$P$ & 0.8534 & 0.4214 & 0.5523 & 0.5448 & 0.6562 & 0.2631 & 0.1142 & 0.1387 & 0.4161 \\
\hline \multicolumn{10}{|l|}{ Recreation } \\
\hline$\beta$ & 0.12 & 0.04 & 0.20 & 0.02 & 0.17 & 0.09 & 0.07 & -0.03 & 0.03 \\
\hline$F$ & 0.02 & 3.33 & 3.40 & 4.89 & 0.47 & 1.95 & 10.28 & 1.27 & 5.95 \\
\hline$P$ & 0.9745 & 0.0723 & 0.0738 & 0.0326 & 0.4915 & 0.1627 & 0.0013 & 0.2594 & 0.0135 \\
\hline \multicolumn{10}{|l|}{ Satisfaction } \\
\hline$\beta$ & 0.03 & 0.04 & 0.19 & 0.02 & 0.03 & 0.18 & 0.07 & -0.09 & 0.08 \\
\hline$F$ & 1.50 & 23.89 & 36.66 & 4.25 & 1.06 & 8.48 & 10.27 & 10.34 & 74.85 \\
\hline$P$ & 0.2267 & 0.0001 & 0.0001 & 0.0439 & 0.3782 & 0.0032 & 0.0014 & 0.0013 & 0.0001 \\
\hline \multicolumn{10}{|l|}{ GSA } \\
\hline$\beta$ & 0.02 & 0.03 & 0.10 & 0.11 & 0.02 & 0.29 & 0.07 & -0.07 & 0.03 \\
\hline$F$ & 3.75 & 8.51 & 90.25 & 1.03 & 0.29 & 5.49 & 10.26 & 7.55 & 14.94 \\
\hline$P$ & 0.1626 & 0.0035 & 0.0001 & 0.3117 & 0.5926 & 0.0225 & 0.0014 & 0.0060 & 0.0001 \\
\hline \multicolumn{10}{|l|}{ Employment } \\
\hline$\beta$ & 0.02 & 0.01 & 0.11 & 0.24 & 0.04 & 0.01 & 0.07 & -0.02 & -0.05 \\
\hline$F$ & 7.01 & 8.00 & 8.76 & 1.35 & 0.85 & 3.23 & 10.88 & 2.30 & 10.10 \\
\hline$P$ & 0.0084 & 0.0045 & 0.0034 & 0.2452 & 0.3665 & 0.0782 & 0.0011 & 0.1292 & 0.0015 \\
\hline \multicolumn{10}{|l|}{ Household } \\
\hline$\beta$ & -0.07 & -0.02 & -0.15 & 0.09 & -0.19 & 0.16 & 0.07 & -0.03 & -0.19 \\
\hline$F$ & 1.21 & 2.47 & 0.04 & 9.23 & 0.03 & 12.20 & 10.24 & 0.01 & 0.03 \\
\hline$P$ & 0.2718 & 0.1257 & 0.8426 & 0.0024 & 0.8756 & 0.0005 & 0.0014 & 0.9164 & 0.0967 \\
\hline \multicolumn{10}{|l|}{ Mate relations } \\
\hline$\beta$ & 0.02 & 0.22 & 1.07 & -0.24 & 0.21 & 0.31 & -0.21 & -0.20 & 0.12 \\
\hline$F$ & 1.52 & 20.88 & 73.70 & 2.18 & 0.91 & 4.32 & 0.90 & 7.77 & 32.87 \\
\hline$P$ & 0.2184 & 0.0001 & 0.0001 & 0.1439 & 0.3435 & 0.0424 & 0.3430 & 0.0054 & 0.0001 \\
\hline
\end{tabular}




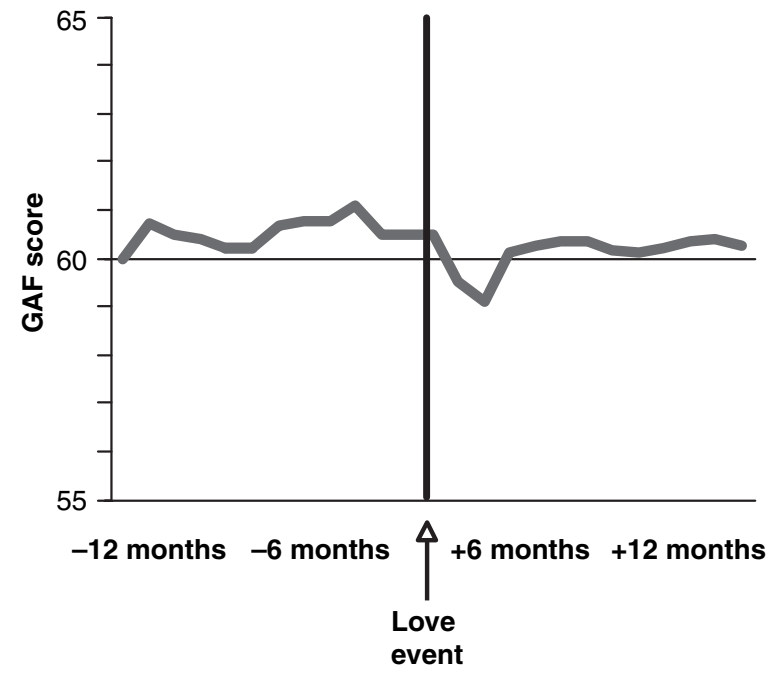

Fig. 1. GAF functioning relative to time that event started.

shows the time course for GAF scores relative to the month in which a negative love event was reported. The data in this figure are group average data, and do not necessarily represent the course of functioning for individual cases. Nonetheless, we believe they accurately show the general trends detected in the longitudinal random effects analyses. GAF scores decline right around the time of the negative love event, and continue to decline for a short period. Our data indicate that GAF levels begin to improve gradually several months after the negative love event was reported.

Interaction effects with $P D$ diagnostic groups Of particular interest to this study was whether or not PD diagnostic groups differed in the strength of the relationship between life events and functioning. One significant interaction was found between positive events and PD diagnostic group in relation to functioning in romantic relationships $(F=3.45, P=0.009)$. Post hoc tests comparing the PD diagnostic groups in the strength of the relationship between positive events and functioning in romantic relationships revealed significant differences between STPD vs. BPD subjects $(t=$ 3.26, $P<0.001)$. Running models separately for each diagnostic group revealed that for every increase in the number of positive events reported in the prior month, romantic relationship functioning scores for STPD subjects improved by twothirds of a point $(F=14.32, \quad P<0.001)$ but declined for BPD subjects by one-tenth of a point $(F=0.10, P=0.19)$.

Interaction effects with neuroticism We also examined whether neuroticism affected the strength of the relationship between life events and functioning. With regards to GAF functioning, a significant interaction between neuroticism and health events $(F=7.12, P=0.0076)$ was found. Probing the health event interaction with neuroticism, subjects with higher levels of neuroticism had a significantly steeper decline in GAF functioning in the month following the health event in comparison with those with lower levels of neuroticism.

\section{Discussion}

The results of this study confirm the findings of Perry et al. (17) that patients with borderline PD experience more total negative recent life events than patients with other PDs or with mood disorders. In addition, we showed that these elevations in rates were characterized by high rates of interpersonal-related life events and to a lesser degree by events related to health and crime/ legal matters. The elevated frequencies of crime/ legal events and social matters are consistent with patterns of criminality sometimes observed in patients with BPD because of their characteristic impulsivity (32), and with the widespread interpersonal dysfunction characteristic of BPD (14).

In addition, we found that patients with STPD also had higher rates of crime and legal events than did patients with the less severe and more constricted PDs of DSM-IV's anxious, fearful cluster C. We are unaware of previous studies of either life events or criminal behaviour in patients with STPD. However, STPD has long been hypothesized to be on the schizophrenia spectrum (33). Epidemiological evidence indicates that patients with schizophrenia have a higher likelihood to commit violent acts (34) and clinical lore suggests that some withdrawn and solitary (but non-psychotic) individuals also have the capacity for violence (35).

Negative events, especially interpersonal-related stressors, predicted decreased psychosocial functioning over time, but the effects were small. Our results are consistent with others who noted the particular impact of interpersonal-related stressful events on impairment in studies of depression, particularly those involving separation and interpersonal loss $(3,36)$. Importantly, the effects of life events on functioning were generally broad, as opposed to domain-specific. Thus, although a work-related life event predicted only decreased functioning at work, a negative romantic life event or a negative family event predicted decreased functioning in several domains unrelated to relationships or to family, as well as on global functioning. Surprisingly, PD diagnosis and 
neuroticism also had only small effects on the relationship of recent life events to functioning. One possible explanation for paucity of findings with respect to neuroticism is the restricted range of possible values - patients with PDs are concentrated on the high end of this scale in this investigation and others (13). In several instances, neuroticism showed trends toward significance, but was not significant at $P<0.01$.

It is interesting that the positive events predicted more pronounced increases in functioning within romantic relationships among STPD subjects in comparison with BPD subjects. On average, STPD and BPD subjects both had low levels of positive events across the study period and both have been shown to have significantly worse functioning in romantic relationships in comparison with AVPD, OCPD, and MDD subjects (14). Because STPD subjects infrequently experience positive events, particularly in close relationships, they may over report improvement in relationships when positive events do occur, as opposed to BPD subject who characteristically have unstable relationships. A complete model of the relationship of positive life events to impairment in social functioning in patients with PDs may need to take into account (and to measure directly and extensively) subjective evaluation of positive events and the problems experienced within romantic relationships in order to more fully understand the mechanisms involved.

\section{Limitations}

There are several limitations regarding the measurement of life events that need to be considered. First, our assessment of life events did not include minor daily hassles that have been associated with the course of axis II disorders (37). Second, our analysis method focused on relatively enduring effects of stress. Dips in functioning lasting only 1 or 2 weeks may not have shown up in the functioning ratings which were recorded monthly, but even if they did, power to detect relatively transient effects (a dip lasting only 1 or 2 months) was low. Very long-delayed effects may also have been hard to detect. Third, we only studied the effects of domains of stressful events (e.g. workrelated events); clusters of stressful events across domains, or the possible cumulative toll of a series of events over a time period greater than 1 month were not considered in these analyses. Fourth, our analyses were based around the month in which a stressor occurred. Some stressors can persist for a number of months. Our analyses did not take the duration of stress into account. However, even with these limitations, our analyses demonstrate the utility of prospective data collection and modern analytical methods to shed light on the magnitude and time course of the effects of stress on functioning.

\section{Acknowledgements}

Supported by NIMH grants MH 50837, 50838, 50839, 50840, 50850, and K05 MH 01645.

This publication has been reviewed and approved by the Publications Committee of the Collaborative Longitudinal Personality Disorders Study.

\section{References}

1. PARIS J. Social Factors in the personality disorders: a biopsychosocial approach to etiology and treatment. New York: Cambridge University Press, 1996.

2. Kendler KS, Neale M, Kessler R, Heath A, Eaves L. A twin study of recent events and difficulties. Arch Gen Psychiatry 1993;50:789-796.

3. Brostedt EM, Pedersen NL. Stressful life events and affective illness. Acta Psychiatr Scand 2003;107:208-215.

4. Kendler KS, Eaves LJ. Models for the joint effect of genotype and environment on liability to psychiatric illness. Am J Psychiatry 1986;143:279-289.

5. Grilo CM, Mcglashan TH. Stability and course of personality disorders. Curr Opin Psychiatry 1999;12:157-162.

6. Costa PT, Widiger TA (eds). Personality disorders and the five-factor model of personality. Washington, DC: American Psychological Association, 1994.

7. Magnus K, Diener E, Fuitta $F$ et al. Extraversion and neuroticism as predictors of objective life events: a longitudinal analysis. J Pers Soc Psychol 1993;65:1046-1053.

8. Breslau N, Davis GC, Andreski P. Risk factors for PTSDrelated traumatic events: a prospective analysis. Am J Psychiatry 1995;152:529-535.

9. Bolger N, Zuckerman A. A framework for studying personality in the stress process. J Pers Soc Psychol 1995;69: 890-902.

10. Eysenck HJ, Eysenck SBG. Manual of the Eysenck Personality Questionnaire. San Diego, CA: Educational and Industrial Testing Service, 1975.

11. Watson D, Clark LA. Behavioral disinhibition versus constraint: a dispositional perspective. In: WEGNER DM, Pennebaker JW (eds). Handbook of mental control. Englewood Cliffs, NJ: Prentice-Hall, 1993.

12. Bolger N, Schilling EA. Personality and the problems of everyday life: the role of neuroticism in exposure and reactivity to daily stressors. J Pers 1991;59:355-386.

13. Morey LC, Quigley BD, Sanislow CA et al. Substance or style? An investigation of the NEO-PI-R validity scales. J Pers Assess 2002;79:583-599.

14. Skodol AE, Gunderson JG, Mcglashan TH et al. Functional impairment in patients with schizotypal, borderline, avoidant, or obsessive-compulsive personality disorder. Am J Psychiatry 2002;159:276-283.

15. PARIS J. Childhood trauma as an etiological factor in the personality disorders. J Pers Disord 1997;11:34-49.

16. Perry JC. A prospective study of life stress, defenses, psychotic symptoms, and depression in borderline and antisocial personality disorders and bipolar type II affective disorder. J Pers Disord 1988;2:49-59.

17. Perry JC, Lavori PW, Pagano CJ, Hoke L, O’Connell Me. Life events and recurrent depression in borderline and 
antisocial personality disorders. J Pers Disord 1992;6:394407.

18. Kelly TM, Soloff PH, Lynch KG, HaAs GL, Mann JJ. Recent life events, social adjustment, and suicide attempts in patients with major depression and borderline personality disorder. J Pers Disord 2000;14:316-326.

19. SiEver LJ, DAvis KL. A psychobiological perspective on the PDs. Am J Psychiatry 1991;148:1647-1658.

20. Gunderson JG, Shea MT, Skodol AE et al. The Collaborative Longitudinal Personality Disorders Study: development, aims, design, and sample characteristics. J Pers Disord 2000; 14:300-315.

21. Zanarini MC, Frankenburg FR, Sickel AE, Yong L. The Diagnostic Interview for DSM-IV Personality Disorders (DIPD-IV). Belmont, MA: McLean Hospital, 1996.

22. First MB, Gibbon M, Spitzer RL, William JBW. Structured clinical interview for DSM-IV Axis I disorders - Patient version (SCID-I/P). New York: Biometrics Research Department, New York State Psychiatric Institute, 1996.

23. Clark LA. Schedule for Nonadaptive and Adaptive Personality (SNAP). Minneapolis, MN: University of Minnesota Press, 1993.

24. Shea MT, Glass DR, Pilkonis PA, Watkins J, Docherty JP. Frequency and implications of personality disorders in a sample of depressed inpatients. J Pers Disord 1987;1: $27-42$.

25. Mcglashan TH, Grilo CM, Skodol AE et al. The Collaborative Longitudinal Personality Disorders Study; baseline axis $\mathrm{i} / \mathrm{II}$ and II/II diagnostic co-occurrence. Acta Psychiatr Scand 2000;102:256-264.

26. Hollingshead AB, Redlich FC. Social class and mental illness. Oxford: Wiley, 1958.
27. Costa PT, Mccrae RR. Professional manual: revised NEO Personality Inventory (NEO-PI-R) and NEO Five-Factory Inventory (NEO-FFI). Odessa, FL: Psychological Assessment Resources, 1992.

28. Costa PT, Mccrae RR. Normal personality in clinical practice: the NEO Personality Inventory. Psychol Assess 1992;4:5-13.

29. Keller MB, Lavori PW, Friedman B et al. The longitudinal interval follow-up evaluation. Arch Gen Psychiatry 1987;44:540-548.

30. Aiken LS, West SG. Model and effect testing with higher order terms. In AIKEN LS, West SG, (eds). Multiple regression: testing and interpreting interactions. Newbury Park, CA: Sage, 1991.

31. Cohen J. Statistical power analysis for the behavioral sciences, 2nd edn. New York: Academic Press, 1988

32. CoID JW. DSM-III diagnosis in criminal psychopaths: a way forward. Criminal Behav Ment Health 1992;2:78-89.

33. ToRgersen S. Relationship of schizotypal personality disorder to schizophrenia: genetics. Schizophr Bull 1985;11: $554-563$.

34. Stueve A, Link BG. Violence and psychiatric disorders: results from an epidemiological study of young adults in Israel. Psychiatr Q 1997;68:327-342.

35. STONE MH. The personalities of murderers: the importance of psychopathy and sadism. In: SKODOL AE, ed. Psychopathology and violent crime. Washington, DC: American Psychiatric Press, 1998.

36. PAYEK ES. Life events and affective disorders. Acta Psychiatr Scand 2003;108:61-66.

37. Malla AK, Cortese L, Shaw TS, Ginsberg B. Life events and relapse in schizophrenia. Soc Psychiatry Psychiatr Epidemiol 1990;25:221-224. 